\title{
Using experiential marketing to leverage the small and medium-sized enterprises' brand repositioning and revitalisation
}

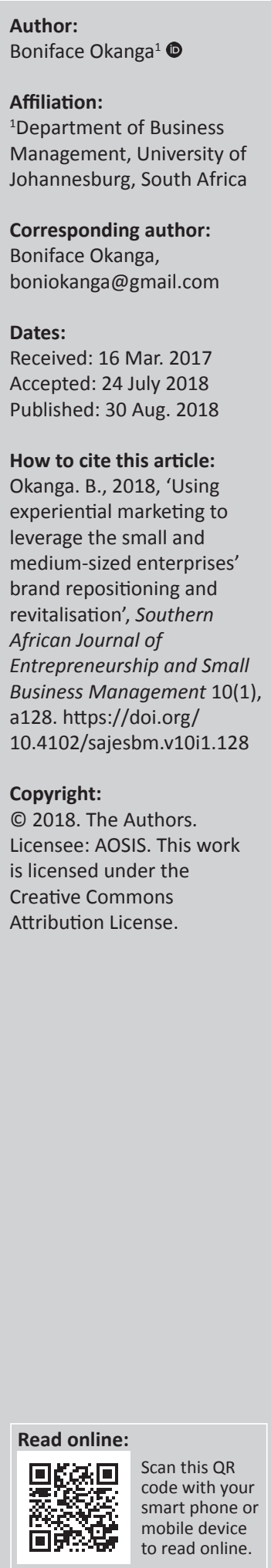

Background: It is easily discernible from theories that experiential marketing spawns frequent brand diagnosis, repositioning and revitalisation. However, the question as to how it can be used to leverage the repositioning and revitalisation of the usually struggling small and medium-sized enterprises (SMEs') products is an area that has not been explored in most of the contemporary studies on how to improve SMEs' market performance.

Aim: This research explores how experiential marketing can be effectively utilised to facilitate the repositioning and revitalisation of the usually struggling SMEs' products.

Setting: The study was based on the SMEs in the Gauteng and Western Cape provinces in South Africa.

Method: The study used an inductive-exploratory-qualitative research paradigm to explore the opinions of 30 SMEs' marketing managers on the values and challenges of using experiential marketing to undertake relevant brand diagnosis, repositioning and revitalisation. It is through such analysis that the study aimed to discern how experiential marketing can be effectively used to facilitate the repositioning and revitalisation of the usually struggling SMEs' products.

Results: However, most of the SMEs were only found to use experiential marketing to leverage not only their promotion and marketing capabilities, as well as sales and profitability maximisation, but also the minimisation of the costs of marketing. Such approach was found to limit SMEs' capabilities to proactively undertake brand diagnosis to identify the inhibitors of a brand's effective market performance that must be addressed to turn around the performance of their struggling products or business concepts.

Conclusion: Considering that not much research has been conducted in this area, the study concludes with the experiential marketing framework that explicates how experiential marketing leverages brand diagnosis, repositioning and revitalisation.

\section{Introduction}

Experiential marketing leverages frequent brand repositioning and revitalisation. As experiential marketing uses intense customer-product interactions to facilitate promotion and sale of the product to the target market segments, it also enhances in-depth evaluation and understanding of the degree of customers' emotional attachments to a brand. This aids brand diagnosis and the identification of the areas of customer dissatisfaction that must be reviewed and modified to bolster a brand's repositioning and revitalisation (Murane 2012:3). Brand repositioning refers to the process of diagnosing, identifying and correcting quality, attributes, functionality, distribution and marketing strategies' issues that could be affecting a brand's effective market performance, so as to turn around the performance of the struggling brands (Jain \& Lohia 2014:197). Brand repositioning also edifies brand revitalisation. Brand revitalisation is the process of diagnosing and refreshing brands that could have turned obsolete to ensure that they are effectively responsive to the changes in the market trends that could have unfolded since the brand's inception (Zarantonello \& Schmitt 2014:255). As brand repositioning and revitalisation require intense brand diagnosis and evaluation, experiential marketing, therefore, offers a framework against which such evaluations are undertaken.

Experiential marketing is a postmodern strategic marketing paradigm that uses intense customerproduct-salesforce interactions as a marketing approach for promoting the sale and consumption of a product among the selected market segments. It relies on the cognitive six senses of smell, vision, taste, hearing, touch and balance to identify and activate customer touchpoints and 
triggers that ignite customers' emotional attachment to a brand (Gronlund 2013:19). It is during such a process that experiential marketing aids brand diagnosis and identification of how the struggling brands can be repositioned and revitalised. This is attributable to the fact that it stimulates marketing executives' abilities to gain detailed insights into customers' level of appreciation or dissatisfaction with the brand. If customer experience and emotional attachments are not supportive of the identified brands, experiential marketing enhances acquisition and assimilation of new information that aids relevant review and modification of a product's designs, features, attributes and quality of the associated customer services to reposition and revitalise more struggling brands (Alkilani, Ling \& Abzakh 2013:262). This bolsters marketing executives' abilities to sense symptoms of eminent brand declines and to undertake proactive intervention strategies to avoid such declines. It also minimises risks of brand obsolescence to subsequently spur improvement of a firm's overall sustainability. However, as the leveraging effects of experiential marketing on a firm's marketing and promotional capabilities have been widely explored by most of the contemporary studies (Day 2011:183; Gronlund 2013:19; Lee \& Chang 2012:103), only little seems to have been undertaken to evaluate its leveraging effects on brand repositioning and revitalisation. It is against that backdrop that this study explores how experiential marketing can be effectively utilised to facilitate the repositioning and revitalisation of the usually struggling small and mediumsized enterprises' (SMEs') brands or products. Considering that leveraging SMEs' sustainability is a challenge that still confounds most of the contemporary business executives, this research is of significant importance on the basis that it offers new insights on how experiential marketing can be used to encourages SMEs' effective market performance.

\section{Literature review}

The logic that experiential marketing edifies brand evaluation and review to spur brand repositioning and revitalisation is implicitly discernible in most of the contemporary theories on experiential marketing and brand repositioning and revitalisation (Adeosun \& Ganiyu 2014:21; Day 2011:183; Dev \& Chekitan 2012:5; Fang-Chao 2015:52; O'Guinn, Semenik \& Scheinbaum 2015:19; Russo et al. 2012:21).

\section{Experiential marketing}

Experiential marketing does not only facilitate intense customer interactions with the product but also provide opportunities for firms to interact and engage with customers (Day 2011:183). This enables thorough evaluations of their overall actual experience with the product. It is through such an approach that marketing executives are often able to understand and identify the areas they could have scored it wrongly or rightly, so as to undertake relevant modifications to reposition or revitalise the struggling brands. Such areas of customer experience often constitute of experiential subject, experiential object and experiential process (Russo et al. 2012:21). Experiential subject refers to the process of undergoing the actual experience of the product. It is in such process that experiential effects that often instigate the decision to buy or not to buy reside. Experiential object is what is actually experienced. Experiential process arises from the acts of sensorially, emotionally, intellectually, imaginatively, physically, socially and spiritually experiencing the experiential object by the experiential subject (Russo et al. 2012:21). To create different experiences that influence purchase decisions, Schmitt's (1999) Strategic Experiential Modules (SEMs) propose five experiences that businesses can create for their customers. These integrated Schmitt's (1999) five experiences include sensory, affective, creative, cognitive and physical behaviours and lifestyles, and social identity experience. Failure of a product to offer all these forms of experience implies that its market performance may not be that impressive. Such insights should, therefore, cause the need for the review and repositioning of such a product. Sensory experience uses sense marketing to instigate and improve a product's appeal to customers through any of the five senses that encompass sight, sound, touch, taste or smell. It creates and adds values that excite a customer to in turn instigate emotions that influence the formation of positive judgements of behavioural, emotional, cognitive, relational and symbolic values about the product or services being offered (Crain \& Abraham 2008:29). Through this process, sensory marketing aids the merging of emotional with rational mental attributes for a customer to develop a more positive perception and attitude towards the brand. Affective experience marketing focuses on exploring and developing customers' moods and feelings from less positive moods to strong emotions that are often characterised by joy and satisfaction (Anderson, Kumar \& Narus 2007; Schmitt 1999).

However, improvement of customers' moods and feelings from the weakest to the strongest levels may require indepth analysis and understanding of customers' behaviours on marketing the product, purchase, consumption and disposal of the product (Aronne \& Vasconcelos 2009:19; O'Guinn et al. 2015:19; Schmitt 1999). Critical analysis and understanding of these processes enable firms to add or modify attributes that leverage improvement of customer moods and feelings to excitement, joy and satisfaction as they undergo the product's purchase and consumption processes (Anderson et al. 2007; Schmitt 1999). As it is often at the consumption level that customer moods and feelings about the product improve, it is often of essence that intense customer interactions and contacts with the product are facilitated during the marketing stage. This enables customer's evaluation of all the aspects of the product. If positive, it may instigate joy and excitement that in turn also influence immediate customers' purchase decisions ( $\mathrm{Xu}$ et al. 2015:53). However, that may still depend on how creative cognitive experience marketing is integrated in such a process to permit customer's free thinking and formation of mental judgement as he or she undergoes through relevant search, purchase and consumption processes (Lefi \& Gharbi 2011:187; Merchant \& Ford 2008:13). 
Such approach improves the level of customer involvement, as well as feedback for the executives to re-evaluate how the existing products and brands are able to instigate positive customer experience, joy and satisfaction (Xu et al. 2015:53). To evoke enormous customer feedbacks, thought-provoking marketing that creatively relies on technologies may be used to surprisingly, intriguingly and provocatively instigate customers to think and evaluate a product. This elicits critical customer information for marketing executives in order to understand how customers feel prior to the consumption of the product or after (O'Guinn et al. 2015:19). To accomplish this, physical experience, behaviours and lifestyles, as well as the relational and social identity of the customers, are often further evaluated and targeted to instigate and improve customers' emotional attachments and attractions to the product. Such a view seems to echo the reasoning in Carù and Cova's (2008:33) theory that heralds consumption experience to unfold over time according to four stages that encompass pre-consumption, purchasing, core consumption, and memories and nostalgic experience. It is the customer's experience along these four stages that influences his or her decisions and future actions in as far as the purchase and consumption of a particular brand are concerned (Carù \& Cova 2008:33; Yu et al. 2014:757). However, effective response to the initial stages of customer experience in which expectations are created to influence search and planning decisions may require investment in social media videos to permit customers to experience, interact, question and test product functionalities (Russo et al. 2012:21). The application of such technologies is often accompanied by the use of events in which prospective customers are encouraged to physically test, try and interact with the product (Jonk, Handschuh \& Niewiem 2008:24). This creates opportunities for businesses to undertake brand diagnosis to identify and correct the areas that customers are not satisfied with. It is at that level that experiential marketing may leverage brand repositioning and revitalisation.

However, Masterman and Wood (2008:1) herald seven attributes that often entice customer experience to arise from customer involvement with the event, experience and brands that instigate customer emotions, interactions with the brand and immersion of all senses. The other attributes are often associated with the development and nurturing initiatives that cause high impact intensity. In turn, such high impact intensity instigates pleasurable memories, customer individuality of experience, innovative improvements of contents, locations, timing and the overall operational efficiency (Masterman \& Wood 2008:1). These attributes are often accompanied by the initiatives for improving the overall integrity of the business by offering real, authentic and genuine benefits to customers. As firms apply such measures to achieve the desired experiential marketing outcomes, customer immersion is often used as one of the critical techniques for experiential marketing (Masterman \& Wood 2008:1). Customer immersion refers to the process of exposing customers to the product or the brand as much as possible to influence improvement of customers' understanding of the brand as well as to discern how they connect to the brand (Dev \& Chekitan 2012:5).

To ensure the process of immersion improves customer's connection with the brand, it is of essence to improve the flow of immersion processes according to three main steps: nesting, investigating and stamping (Dev \& Chekitan 2012:5). Nesting refers to the stage where opportunities are created for customers to interact, question and understand the brand until they feel comfortable and satisfied. This process of familiarisation often leads to the investigation stage where customers tend to explore further values that not only ignite their emotions but also further connect them to the brand. As the customer gets more connected to the product, stamping stage arises to influence the use of the experience gained as points of reference to make necessary decisions (Zarantonello \& Schmitt 2014:255). To accomplish that, businesses may also have to invest in relevant online marketing technologies as well as multimedia videos that permit customers to evaluate information and ask questions (Zarantonello \& Schmitt 2014:255). It is through such questions that businesses can be able to identify common igniters of customers' emotions that must be capitalised on to catalyse a product's overall effective market performance.

Effective use of customer immersion as part of the techniques for experiential marketing is also often further edified by the use of hedonistic and instrumental events $(\mathrm{Hu}, \mathrm{Ho} \&$ Hsieh 2014:55; Masterman \& Wood 2008:1). Hedonistic events constitute of activities such as sports, art and music that are often directed to the largely younger segments of the market that tend to construe pleasure as the most important thing (Masterman \& Wood 2008:1). Quite often, events of instrumental purposes constitute of activities such as sampling, trade shows and consumer shows. It is the use of these events that enhances thorough evaluation and diagnosis of customer's attachments to the brand. In other words, if undertaken well, all these imply that experiential marketing not only aids brand diagnosis to improve the market performance and repositioning of the existing brands but also aids revitalisation of the older brands that could have turned obsolete (Canniford 2011:591; Crain \& Abraham 2008:29; Marzocchi, Morandin \& Bergami 2013:93).

\section{Brand repositioning}

Brand repositioning refers to the process of diagnosing, identifying and correcting quality, functionality, attributes, distribution and marketing strategy issues that could be affecting a brand's effective market performance, so as to turn around the performance of the struggling brands (Kolbl, Konecnik \& Kolar 2015:5; Zdravkovic \& Till 2012:113). Quite often, brand repositioning requires a product's review and modification, as well as the review and adoption of new marketing strategies such as distribution, promotion and pricing to target the appropriate market segments (Dev \& Chekitan 2012:5; Kolbl et al. 2015:5). It also requires brand re-evaluation and redesign, reinventing brand identity, 
innovative advertising, refreshing of the visual aspect of the brand and expansion of the brand's portfolio of products (Dev \& Chekitan 2012:5; Zarantonello \& Schmitt 2014:255). However, conventional theories on brand repositioning imply whether or not the application of such strategies is required, depending on the results of the analysis of the overall level of brand maturity (Kolbl et al. 2015:7; Zarantonello \& Schmitt 2014:255).

The level of brand maturity is best diagnosed by assessing brand, price, sales, and technology and investment dimensions (Kolbl et al. 2015:7). The analysis of brand dimension enhances the understanding of whether the level of brand awareness, points-of-differentiation, long-held heritage and brand association with the target market are narrowing down (Kolbl et al. 2015:7; Zarantonello \& Schmitt 2014:255). Narrowing brand dimension suggests the brand is losing its market relevance. However, it is usually still of essence to analyse in conjunction with the evaluation of the sales dimension. Sales dimension's analysis facilitates the assessment of whether sales have started to stagnate or decline. It also requires the evaluation of the effectiveness of the distribution networks of the brand, a brand's ability to generate profits and the extent to which it is or it is not losing most of its loyal customers. Quite often, such analysis may also encompass price dimension evaluation to assess whether a brand's poor performance is arising from poor pricing or under-investments in the appropriate marketing strategies (Gupta \& Ramachandran 2010:4).

Technology and investment dimension diagnoses whether a brand's declining market performance is arising from the outdatedness of the technology being used, not upgrading product quality, poor management focus and limited investments in the required sales and marketing activities (Gupta \& Ramachandran 2010:4). Through experiential marketing and other forms of survey, marketing executives are often able to understand the extent to which the market relevance of a particular brand is increasingly being eroded. If a particular brand is found to have reached the maturity level to an extent that it can no longer generate the required returns on shareholders' value, some of the brand repositioning strategies often entail expanding brand awareness and usage, improving brand image and uniqueness of brand association, and managing how the existing users select mature brands (Keller 2013a:19).

Expanding brand awareness and consumption may require increment of investment in promotional and marketing budgets, changing packaging, identification of new market segments to target and introduction of the mature brand either as supplementing another product or as being supplemented by another brand (Keller 2013b:19). Improvement of brand image and uniqueness of brand association are often effected by identifying and targeting new customer segments. It may also require the development and utilisation of multiple marketing communication strategies that use array of messages that reposition the brand in a new away. Alternatively, businesses that are facing challenges of brand maturity may also have to conceptualise and apply new strategies such as loyalty programmes to retain the existing customers while also attracting new ones. Such initiatives are usually undertaken in conjunction with the evaluation and management of how the existing customers choose mature brands, so as to improve the market performance of the existing brands through improvement of the brand's availability and use of multiple or alternative shelf placements.

Development of new distribution outlets may be accompanied by the improvement of the features, designs and quality of the existing brand to ensure that it compares more superiorly with the other brands (Aronne \& Vasconcelos 2009:5). Besides altering packaging to increase usage, the other strategies would be the association of the brand with certain unique specific values, decreasing price per unit and developing sub-brands through brand extension to increase the consumption and sale of more mature brands (Qader 2013:331). Although the application of such strategies can edify brand repositioning and revitalisation, the notions of brand repositioning and revitalisation are still cyclical processes that must be frequently undertaken to ensure that brands are repositioned and revitalised to remain relevant to the unfolding market and industry changes (Qader 2013:331).

\section{Brand revitalisation}

Brand revitalisation is the strategic process of re-awakening brands that are expressing significant declines or that are on the verge of fading away from the market (Iglesias, Singh \& Batista-Foguet 2011:570). Brand declines are often caused by the changes in the market and industry trends, emergence of better brands and changes in technology that may render the existing technologies obsolete (Iglesias et al. 2011:570). In certain instances, brand declines are also instigated by the application of poor marketing strategies that may require the introduction of new brands that would probably also fail to impress the market. This causes a negative brand image that affects not only the extended brands but also the brand that previously enjoyed a positive brand image (Keller 2013b:33). In the event of brand decline, Light and Kiddon's (2009) brand revitalisation model which is replicated from the McDonald's model of brand revitalisation highlights the process of brand revitalisation to take six steps. These six steps entails refocusing the business, restoring brand relevance, reinventing brand experience, reinforcing a result culture, rebuilding brand trust and global realignment of the brand.

However, Murane's (2012) model for brand revitalisation suggests the process of brand revitalisation to require the use of seven main steps that entail developing a consensus on the problems that are affecting the brand's performance, negotiating the time horizon to fix the problem, resource acquisition and trends' alignment. It also entails investment in technology replenishment, reframing brand image and 
strategy, and the use of effective marketing communication strategies (Keller 2013a:10). On the contrary, other authors share similar views that the development and application of seven steps is critical for enhancing the effectiveness of brand revitalisation (Adeosun \& Ganiyu 2014; Chao \& Kuo 2013:33; Kotler \& Armstrong 2010:114). These seven steps that significantly differ from the seven steps in Murane's (2012) model for brand revitalisation are repeated to require brand audit, evaluation of brand positioning, developing a brand platform, establishing brand beliefs, evoking brand experience, developing a brand voice with launching a new brand. Brand audit often requires the evaluation of the unique historical facts that distinguished and set the product and the company apart vis-à-vis the current brand's current operations, communications and positioning. Such an analysis enhances the diagnosis and identification of the sources of paradoxes marring the effectiveness of a brand's performance. This leads to the analysis and identification of a new brand positioning, platform, beliefs, experience, voice and launch that must be created to revitalise the brand (Herrmann, Walliser \& Kacha 2011:259).

Certainly, it is implicitly evident that experiential marketing edifies diagnosis and understanding of the level of customer attachments, emotions and feelings of the brand. Lack of emotional attachments and positive feelings among most of the customers signifies that the brand is not competitive against most of its rivals (Kanth, Maheswar \& Venkatesulu 2016:321). Symptoms of these are often easily discernible in the increasing rates of customer defection, complaints, declining sales, revenues and profitability. Through experiential marketing, the identification of these symptoms often offers warning signs that imply firms need to reposition and revitalise the struggling products or brands in order to remain sustainable (Kanth et al. 2016:321). Unfortunately, despite evidence of the fact that most SMEs struggle to operate sustainably, only mundane evidence seems to suggest that most of the SMEs have often explored how experiential marketing can be used to leverage the repositioning and revitalisation of their usually struggling brands (Lekhanya 2015:37; Rootman \& Zeka 2013:1). Such an approach often affects the initiatives of turning around the performance of the brands that could have been repositioned and revitalised to improve not only the brand's effective market performance and sustainability but also the competitiveness and sustainability of the entire enterprise. Even though brand repositioning and revitalisation establish a firm's sustainability, the feasibility of SMEs doing so seems yet elusive in most of the contemporary studies.

\section{Small and medium-sized enterprises' brand repositioning and revitalisation}

Certainly, enormous studies have been conducted on how to improve SMEs' performance (Day 2011:183; Gronlund 2013:19; Ward, Runcie \& Morris 2009:78). However, only limited attempts seem to have been undertaken to explore the strategies for leveraging the repositioning and revitalisation of the SMEs' struggling products. Yet, increasingly, the major threats to SMEs' sustainability often arise from the difficulties of their products or business concepts to withstand the often volatile competitive market forces. In effect, frequent brand diagnosis is critical for understanding the dynamics that could be affecting a brand's effective market performance. In Gang's (2011:11) research on the strategies for brand management in SMEs, brand management was found to be critical for bolstering SMEs' sustainability. It aids the evaluation of the attributes that influence brand performance. As such evaluations are being undertaken, it also enhances discerning the strategies for improving customer's attachment to different brands. As most SMEs struggle to operate more competitively in the midst of the more intense competitive modern markets, Gang (2011:11) suggests the importance for brand awareness and brand extension to minimise risks of brand obsolescence. Gang's (2011:11) views on the importance of brand management also seem to be echoed in Lockwood's (2010:10) argument for the use of the appropriate branding strategies. Lockwood (2010:10) argues that most of the entrepreneurs in most of the SMEs are increasingly recognising branding as one of their most valuable assets which seek to set reputation that distinguish their products from those of the competitors. As businesses increasingly recognise such values of branding, a number of SMEs are also increasingly investing in the creation of distinctive benefits that go beyond the price to distinguish their products or services from those of rivals. It is such strong brands that not only simplify customer decision-making processes but also reduce risks of the SMEs' vulnerability to high levels of industry competition and volatilities (Day 2011:183). In effect, the development and application of the appropriate strategic brand management initiatives is critical for bolstering the competitiveness of SMEs' brands. Such initiatives must be accompanied by the evaluation of the overall connection between the brand and the consumers.

Initiatives must also be undertaken to explore the extent to which customer expectations and perceptions are matched, not only by the product but also by the other complementary factors such as the product's packaging, promotion and pricing (Day 2011:183). Strong branding is also critical for leveraging SMEs' customer relationship management capabilities that in turn induce improved loyalty in the midst of more fierce competition among the masses of SMEs and big businesses. In contrast to such a view, Matthews and Bucolo (2014:5) also reveal that most of the SMEs are increasingly engaging in innovations as a strategy for enriching and modifying the features and attributes of their existing brands to leverage their overall effective market performance. With significant funds committed on research and innovation, Matthews and Bucolo (2014:5) argue that it turns easier for SMEs to engage in brand audit and discern the features and attributes that can be refreshed to turn around the performance of the struggling brands. Despite such values of branding, challenges often still tend to arise from the adequacy of the financial resources that 
SMEs can commit to branding, as well as to the promotional and marketing activities that bolster their brand image (Lockwood 2010:10).

Frequent brand repositioning and revitalisation may require the complete dismantling of the existing products and the development of new ones to respond to the changes that are emerging from the unfolding market trends. Brand repositioning and revitalisation may also require the use of new strategies and intensive advertisements and marketing (Lockwood 2010:10). All these may tend to induce hefty deterring costs that affect the capabilities of the SMEs to reposition and revitalise the performance of their struggling brands. This implies that even if some of the SMEs may recognise frequent brand repositioning and revitalisation as critical for leveraging their continuity and sustainability, the associated required costs may tend to be deterring. However, despite such hefty costs, the values of successful brand repositioning and revitalisation still often offset the hefty costs that they induce (Ward et al. 2009:78). That implies brand diagnosis; repositioning and revitalisation are part of the critical strategies that can be used to establish SMEs' continuity and sustainability in the increasingly competitive modern business environment. However, as such an area has not been widely explored by most of the previous studies, discerning the experiential marketing model that can be used to aid brand diagnosis, repositioning and revitalisation remains a challenge. It is such a challenge that this research seeks to address.

\section{Problem statement}

Using experiential marketing to leverage the repositioning and revitalisation of the usually struggling SMEs' products is an area that has not yet been widely explored by most of the contemporary studies on how to improve SMEs' effective market performance.

\section{Research purpose}

The purpose of this research is to explore how experiential marketing can be effectively utilised to reposition and revitalise the performance of the SMEs' struggling products. To accomplish this, the entire research process was guided by the fundamental research questions that entailed the evaluation of:

- How do SMEs utilise the opportunities availed by experiential marketing to undertake relevant brand diagnosis to reposition and revitalise the performance of their struggling brands?

- What types of changes are usually undertaken as a result of customer opinions and perceptions that are acquired during experiential marketing to aid the repositioning and revitalisation of SMEs' struggling products?

- What challenges do SMEs experience when seeking to undertake changes that are required to reposition and revitalise the performance of their struggling brands and businesses?

\section{Methodology}

To respond to these research questions, the study used the inductive-exploratory-qualitative research paradigm (Chen, Shek \& Bu 2011:129; Wynn \& Williams 2012:787).

\section{Research paradigm}

The application of the inductive-exploratory-qualitative research paradigm was considered critical for responding to the fundamental research question that sought to explore whether, when using experiential marketing, SMEs also utilise such opportunities to undertake relevant brand diagnosis to reposition and revitalise the performance of their struggling brands. The inductive research paradigm often commences with problem identification and subsequently secondary and primary data collection to discern the theory that can be extracted to respond to such a problem (Babbie \& Mouton 2008:11). In contrast, the deductive research approach which is mainly hypotheticallydriven often commences with the formulation of a theory that subsequently guides secondary and primary data collection and analysis to discern whether such a theory is confirmed or contradicted by the findings (Babbie 2008:23). The rationale for the application of the inductive-exploratoryqualitative research approach is accentuated by the fact that certainly, important studies have been conducted on experiential marketing as well as on brand repositioning and revitalisation. However, in most of such studies not much seems to have been undertaken to explore whether experiential marketing generates brand diagnosis, repositioning and revitalisation.

In effect, the application of the inductive-exploratoryqualitative research approach was considered critical for eliciting detailed insightful underlying information on whether, when using experiential marketing, SMEs also utilise such opportunities to undertake relevant brand diagnosis to reposition and revitalise the performance of their struggling brands. While using the inductive research paradigm to accomplish that, the study also used the exploratoryqualitative research methodology. The exploratory-qualitative research methodology refers to the research approach that applies a combination of the techniques such as observation, content analysis and interviews to aid eliciting critical, underlying, detailed information that offers insightful explanation of the phenomenon being researched (Bryman \& Bell 2007:133). Using interviews as the primary data collection technique, the exploratory-qualitative research methodology probed the fundamental research questions that aimed to explore whether SMEs' experiential marketing behaviours enhance brand diagnosis, repositioning and revitalisation, the types of the often undertaken changes, as well as the challenges of undertaking such changes to aid repositioning and revitalisation of the struggling brands. It was from such an analysis that the study was able to discern whether experiential marketing aids brand diagnosis, repositioning and revitalisation. 


\section{Sampling}

To access relevant primary data on SMEs' experiential marketing behaviours, convenience and purposive sampling were used in conjunction with snowballing to identify and draw 30 sample participants that constituted of the marketing managers, as well as senior sales and marketing personnel from 30 SMEs in the Gauteng and Western Cape provinces (Cohen, Manion \& Morrison 2011:19). By the very nature of their work, marketing managers and senior sales and marketing personnel from the marketing departments in the selected 30 SMEs were construed to possess holistic knowledge and understanding of what experiential marketing entails, as well as the value of its application. In effect, from these 30 SMEs, it was the marketing managers and senior sales and marketing personnel that were the focus of the study. In the research which was conducted in the period between July 2016 and January 2017, convenience and purposive sampling techniques were used in conjunction with snowballing to draw 15 SMEs from the Gauteng province and 15 SMEs from the Western Cape province to make a total of $30 \mathrm{SMEs}$. Convenience sampling was used for determining the provinces in which the study could be based. Applying criteria such as costs, ease of data collection and availability of personal contacts in the designated provinces, a decision was undertaken to select the Gauteng and the Western Cape provinces. Basing the study in two or more provinces was considered critical for gaining critical insights and generalisation about the common SMEs' experiential marketing behaviours, as well as whether such behaviours also aid brand diagnosis to enhance the repositioning and revitalisation of the struggling brands. For each of the 30 SMEs to be drawn into the study, purposive sampling required the business to have about 200 employees, a net annual turnover of R5 million or more, 10 years of existence and a presence in either Gauteng or the Western Cape province or in both.

The application of such criteria was aimed at accessing only the SMEs with significant years of relative success and understanding of the industry, as well as how the application of experiential marketing methodologies could have been critical for leveraging their market performance. To ensure compliance with such criteria, thorough analysis of the websites, media reports, grey literature and media reports about 50 SMEs, located in the Gauteng and the Western Cape, were selected. This was followed by the identification and utilisation of any of the previously established contacts in any of the SMEs that exhibited features that met such criteria. It is the brief interviews with such contacts that influenced not only the understanding of whether or not their businesses complied, but also whether some of their business acquaintances and colleagues met the criteria to participate in the study. In the Gauteng, it was 10 of such previously established contacts that influenced additional 5 of their acquaintances and colleagues in the other SMEs to participate in the study. In the Western Cape, 5 previously established contacts influenced additional 10 marketing managers or senior personnel in the SMEs that met the designated criteria to participate in the study. Such previously established contacts made it easier to get consent from others suitable to participate in the study but also enhanced the authorisation and consent for the identified businesses to be used or to participate in the study. This process of snowballing led to the identification of a total of 30 sample participants that constituted of the marketing managers as well as senior sales and marketing personnel from 30 SMEs which were also in turn drawn from 50 SMEs which were analysed for compliance with relevant purposive sampling criteria. The 30 SMEs were mainly drawn from the industries and sectors such as hotel and hospitality, finance, insurance, manufacturing, retail, distribution and logistics handling, clothing retail and fastfoods retail.

\section{Data collection}

In the research which was conducted in the period between July 2016 and January 2017, the methodologies for data collection mainly entailed telephonic and face-to-face interviews. Because of distance, all 15 senior sales and marketing personnel from the Western Cape, as well as five from Gauteng with busy schedules opted for telephonic interviews, while others preferred to do face-to-face interviews on weekends and public holidays. Whether it was telephonic or face-to-face interviews, all interview responses were transcribed as each of the participants offered different narratives on the utilisation of the various experiential marketing methodologies in their businesses. Upon consenting and agreement on the principles of anonymity and confidentiality, all the interviews commenced with brief explanations of the concept of experiential marketing to each of the 30 participants. Even though most of the participants already had a clear understanding of the concept of experiential marketing, this enabled the reaching of the common points of views on what the concept of experiential marketing entails. Thereafter, each of the 30 participants was asked to respond to each of the following interview questions:

- What types of experiential marketing methodologies does your business use quite frequently?

- Why do you prefer to use such experiential marketing methodologies?

- What are the values of experiential marketing?

- Do you use experiential marketing to gain insights into customer opinions and perceptions about certain aspects of your products and business approaches? If yes, how? If no, why?

- How do the customer opinions and perceptions, gained during experiential marketing, influence any review and change of the product and the business approach that your business subsequently adopts? If no, why not?

- What types of changes are usually influenced by the customer opinions and perceptions gained during experiential marketing?

- What challenges do you usually experience when undertaking necessary changes to revitalise the performance of your products and business that are not doing well? 
The design of the interview guide was based on the fundamental research questions that aimed to explore whether SMEs' experiential marketing behaviours enhance brand diagnosis, repositioning and revitalisation, as well as the types of the undertaken changes and the challenges of undertaking such changes. Interviews were semi-structured on the basis that even though such predetermined, structured, open-ended questions were used, further probe and reprobe were permitted. Probe and reprobe were used to enrich the understanding of relevant new insights that were emerging from the interview responses. The obtained interview findings were analysed using the inductive thematic approach.

\section{Data analysis}

Conventionally, qualitative data may be analysed using the deductive thematic approach or the inductive thematic approach (Bryman \& Bell 2007:133). In the application of the deductive thematic approach, the process of analysing and extracting relevant themes and sub-themes is often guided by some predefined theoretical framework. That implies that there is often a greater preponderance to focus on identifying and extracting contracts and discourses that support the assertions in such predefined frameworks. In contrast, the inductive thematic analysis is an open-minded approach that focuses on permitting the natural emergence of relevant themes and sub-themes which offer coherent explanations of the phenomenon being researched. While using the inductive thematic approach in this research, the analysis of the obtained interview findings were undertaken in the context of the research questions with the motive of permitting the organic emergence of relevant themes and sub-themes. In line with the fundamental research questions for this study, the motive of such analysis was to diagnose whether the emerging themes and narratives offer critical insights to whether experiential marketing enhances brand diagnosis, repositioning and revitalisation, as well as the types of changes undertaken and the challenges of undertaking such changes. In the first instance, thorough reading and rereading each interview transcripts were undertaken; thereafter, analysis was undertaken to extract themes and discourses as well as to map themes, sub-themes and their associated narratives across different discourses.

\section{Extraction of themes}

Fetterman's (2009) approach for inductive thematic analysis was used to identify and extract key themes and sub-themes as well as their associated narratives from each participant's responses to each interview question. Such analysis aimed at assessing how experiential marketing enhances brand diagnosis, repositioning and revitalisation, as well as the types of changes made and the challenges of those changes. However, comparison and contrasting of key themes and sub-themes as well as their associated narratives from each participant's responses to identify and extract common themes from all 30 the participants led to the identification of the other values of experiential marketing. Such values of experiential marketing did not only include brand diagnosis and the essence to undertake the required changes to reposition and revitalise the performance of SMEs' struggling brands but also include values such as leverage of the effectiveness of promotion and marketing capabilities, sales and profitability maximisation as well as costs of marketing's minimisation. Other values also encompassed the analysis of the causes of poor performance, declining sales, declining profitability, customer dissatisfaction, and the diagnosis of the effectiveness of the internal capabilities and marketing strategies. Most participants' narratives also indicated that it is often such similar themes that also instigate the need for the use of experiential marketing to either boost sales or undertake necessary diagnosis of customer opinions and perceptions. Because of the complexity of the emerging patterns of themes, categorisation and mapping of themes and their narratives according to their common inherent meanings in as far as the concept of experiential marketing is concerned were undertaken to discern how the emerging themes offered coherent explanations of how experiential marketing enhances brand diagnosis, repositioning and revitalisation, as well as the types of changes and the challenges of making such changes.

\section{Extraction of discourses}

Such classification and categorisation of themes influenced the extraction of three discourses that encompassed the motives, values and challenges of experiential marketing discourses. The discourse of experiential marketing motives was extracted from the common meaning that was attributed to themes such as sales and profitability maximisation, leverage of marketing capabilities, costs of marketing, oneon-one marketing, personal selling, shows, demonstrations, online marketing and turning around declining sales. This is attributable to the fact that from the participants' narratives, these themes were found to constitute the major motives for SMEs to use experiential marketing. The discourse of experiential marketing's values emerged from the common meaning that was attributed to the category of themes, like the analysis of the causes of poor performance, declining sales, declining profitability, customer dissatisfaction, and diagnosis of internal capabilities and marketing strategies' effectiveness according to their common meanings as the values of experiential marketing. It also included themes and their associated narratives on the review and change of product quality, features, pricing, costs, product or service accessibility and distribution strategies' effectiveness. However, drawing from the associated participants' narratives on such themes, the interpretation and linking of the meaning of the themes under the discourse of experiential marketing's values indicated that it is also themes such as poor performance, declining sales, declining profitability and customer dissatisfaction which often instigate SMEs to use experiential marketing to either boost sales or to do the necessary analysis of customer opinions and perceptions. Whereas boost of sales was found to fall under the discourse of experiential marketing motives, the analysis of customer's opinions and perceptions was found to clarify their 
satisfaction and/or dissatisfaction with the product or with a firm's internal capabilities and strategies. Such an analysis influenced the extraction of the discourse on the value of experiential marketing and dividing it in two sub-discourses that encompassed satisfiers and/or dissatisfiers and the firm's various strategies. In effect, common meaning that was attributed to themes and sub-themes on the analysis of the causes of customer dissatisfaction with product quality, features and pricing, costs and product or service accessibility enhanced the extraction of the discourse of satisfiers and/or dissatisfiers' diagnosis. However, from the participants' narratives, the mapping of themes indicated such themes to also arise from the corresponding types of changes or strategies, such as the review of pricing, cost variables and product attributes that some of the SMEs use to respond to such challenges. Sub-discourse of a firm's strategies' diagnosis was extracted from the common meaning that was attributed to the class of themes such as the analysis of the causes of poor performance, costs, internal deficiencies, marketing strategies' deficiencies, declining sales and profitability as well as customer dissatisfaction. From the participants' narratives, the mapping of themes indicated such themes to also link with the corresponding types of changes or strategies such as the review of distribution strategies, marketing approaches and the overall effectiveness of internal capabilities that some of the SMEs use to respond to such challenges.

\section{Mapping}

Despite the categorisation of themes according to three such discourses, mapping still indicated intricate linkage of themes across all discourses. The effect was that the discourse on experiential marketing motives was also explained by some of the themes in the discourse of experiential marketing values such as revitalisation of poor performance, declining sales, profitability and customer dissatisfaction that motivate the aggressive use of online marketing to counter the associated declining performance. Most participants' narratives indicated that it is often such similar themes that instigate the need for experiential marketing to either boost sales or make necessary diagnosis. The discourse of experiential marketing challenges emerged from the common meaning that was attributed to themes such as the costs of marketing, costs of change, complexities of understanding customers' opinions, lack of relevant technologies, management and executives' commitment to change and lack of understanding of the concept of experiential marketing. However, mapping indicated most of the challenges to emerge from the participants' narratives on how such constraints hamper the use of experiential marketing to achieve different business objectives or to undertake relevant diagnosis to reposition and revitalise the performance of the declining products. In effect, themes from the discourse of experiential marketing challenges such as costs of marketing were more discernible from the participants' narratives on why some SMEs opt to use different experiential marketing methodologies as compared to the traditional television, FM radio and newspaper marketing. On the contrary, themes on experiential marketing challenges such as the complexities of understanding customers' opinions, lack of relevant technologies, management and executives' commitment to change and lack of understanding the concept of experiential marketing were more linked to most of the participants' narratives on why SMEs fail to diagnose satisfiers and/or dissatisfiers, as well as SMEs' capabilities to make the required changes. Based on such analysis, findings were structured according to two sections that encompassed the motives of SMEs' experiential marketing and the value of SMEs' experiential marketing. However, as the study was being undertaken, measures were also undertaken to enhance the overall validity and reliability of the study.

\section{Validity and reliability}

In a qualitative research, the validity and reliability are often enhanced by the credibility, dependability and transferability of the study (Lincoln \& Guba 2005:69). Whereas credibility connotes the veracity and plausibility of the findings, dependability refers to the extent to which the findings of the study can be relied on for making relevant decisions. Transferability measures the replicability of the study in another situation that exhibits similar characteristics under which the study was conducted (Bryman \& Bell 2007:133). In this research, credibility, dependability and transferability of the study were enhanced by upholding descriptive, interpretive and theoretical validity and reliability of the study. Descriptive validity was undertaken to improve the factual accuracy of the findings. This entailed ensuring that only the participants with critical understanding of the traditional marketing and experiential marketing approaches were drawn into the sample population. Combined with fact checking, this improved the overall veracity and credibility of the findings (Cohen et al. 2011:19). To further enhance the credibility, dependability and transferability of the findings, descriptive and content validity were enhanced by using an objective approach to eliminate risks of biasness during the process of the accomplishment of the study. Such an initiative was accomplished by exploring both the values and risks of using experiential marketing to undertake brand diagnosis, repositioning and revitalisation. This implies that if the findings of this research are to be used, the understanding of such values, as well as risks would aid in the modifications of the decisions on how experiential marketing can be used to leverage brand diagnosis, repositioning and revitalisation. Such initiatives were accompanied by extension of the periods of data collection to do more interviews until all the desired information about experiential marketing had been gained from the field research. This is accentuated by the fact that although the original major research was conducted in the period between July 2016 and January 2017, further field research was undertaken in the period between March and May 2018 to ensure that all the critical views on SMEs' use of 
experiential marketing were extracted. To further improve the descriptive and content validity of the study, comparison and contrasting the responses from different participants were also undertaken to check the veracity of the findings. Such an approach also improved the interpretive validity and reliability of the findings. Yet, as the findings were being analysed and discussed, further initiatives of leveraging interpretive validity and reliability were undertaken by ensuring that it was mainly the narratives from the participants that were used to avoid the distortion of the messages that the participants aimed to convey. At the same time, corroboration in the views of the participants in the study, as well as the triangulation of the interview findings with theories were also used as one of the methods for improving the interpretive as well as theoretical validity of the study (Bryman \& Bell 2007:133). This also improved the confirmability of the study as well as its credibility and dependability. It also implies that if a similar study was to be conducted again, it is most likely that the findings would still be obtained. Against this backdrop, the details of the interview results are as presented and discussed in the next sections.

\section{Results}

Deriving from the analysis of the interview findings where the categorisation of the emerging themes and their common meanings influenced the extraction of three discourses that encompassed the motives, values and challenges of experiential marketing, the findings are presented:

- motives of SMEs' experiential marketing

- values of SMEs' experiential marketing.

In this analysis and presentation of the findings, themes in the discourse of experiential marketing challenges are integrated as part of the themes that explain the motives or values of experiential marketing. It is through such analysis that the study sought to respond to the fundamental research questions that aimed to explore how SMEs' experiential marketing enhances brand diagnosis, repositioning and revitalisation, as well as the types of the often undertaken changes and the challenges of undertaking such changes. The details are as follows.

\section{Motives of small and medium-sized enterprises experiential marketing}

It is the fundamental view in most theories that experiential marketing offers intense customer-product-salesforce interactive methodologies that can enable businesses to diagnose and improve customer's attachment to the brand. However, in contrast to such a view, most of the SMEs were only found to use experiential marketing to aid the achievement of basic fundamental business outcomes such as sales and profit maximisation, leverage of marketing capabilities and costs of marketing's minimisation. The details of these themes are evaluated as follows.

\section{Sales and profitability maximisation}

Even though the term experiential marketing did not emerge from the views of some of the participants, it was still evident from the findings that some of the SMEs use some form of experiential marketing methodology. Some of the SMEs reiterated that such an experiential methodology entails the use of multimedia videos to augment product demonstration or the demonstration of the services offered by the business. As other SMEs indicated using one-on-one marketing in which the use of the product is demonstrated to the potential customers. Such views were mainly common in most of the responses to the interview question that explored the types of experiential marketing methodologies that SMEs frequently use. However, in the responses to the interview questions that explored why SMEs use such experiential marketing methodologies, experiential marketing was found not to be necessarily used for aiding brand diagnosis, revitalisation and repositioning. Instead, some of the marketing managers revealed that the main purpose of using experiential marketing is usually for stimulating sales and profit maximisation. In the instances of declining sales and revenues, some of the marketing managers reiterated that they have often used an array of multimedia videos and online advertisements to increase customers' awareness of the product's availability. The communication in such multimedia videos often convey messages that inform customers about discounts or the introduction of new products. In such instances, experiential marketing was found to ignite the interests of new customers to visit the store and try out the product. Even if it does not cause retention and loyalty of such new customers, some of the marketing managers still argued that the immediate desired positive effects of experiential marketing are often still easily latent in the increment of sales and revenues. Such a view was corroborated in the opinions of a 37 years old female marketing manager with the work experience of 11 years in foods and beverage manufacturing plant who stated that:

'When sales are less impressive, we usually try to use our online advertisements that constitute of several multimedia videos to inform the public about the discounts or the availability of such products across different stores. This is important for arousing customer interests as well as for reaching out the customers who may not be aware about the availability of such products.' (Female, 37, marketing manager)

As some of the SMEs use experiential marketing to stimulate sales by announcing discounts and price reductions, other marketing managers indicated using multimedia videos only to inform the public about the introduction of new products. They explained that in most of the cases that new products are introduced, the general public except those who frequently visit their stores are usually not aware of the availability of such products. This causes the initial poor market performance of such products. To turn around such poor performance, multimedia videos that demonstrate the use of such new products are usually used in conjunction with newspaper or television advertisements to inform the 
public about the existence of such products. As such information is accompanied by the message of where the products can be found, some of the marketing managers revealed that they often do not go an extra length to find out how customers feel about the product. Even if some of the SMEs do so, findings indicated some of the sales personnel to just often do so as a matter of formality of interacting and building relationship with the customers and not for the purpose of any major anticipated change. In contrast, other marketing managers noted soliciting customers' views on whether they like the product or not to be critical for determining whether or not more of such products can be restocked. It further emerged from the findings that whereas those in the retail sector just abandon the ordering of the poorly performing products, those in the manufacturing sector argued that they often attempt to discern the further changes in strategies or the product's ingredients that can be undertaken to catalyse the improvement of the product's market performance. Such a finding was echoed in the opinions of a marketing manager with work experience of five years in the retail sector who stated that:

'If the response from the customers is not positive and the product continues to perform poorly, we often just discontinue ordering. In most of the cases, when it is a new product, we just take very limited quantity to test what the customers would say. If they are not impressed, we discontinue, if they are impressed, we commit more resources to order more.' (Female, 27, marketing manager)

Such a finding implies that experiential marketing influences change and modifications of the sourcing strategies in the retail enterprises. However, further analysis of the findings indicated that some of the SMEs just use some of the multimedia videos to enrich and improve a product's branding. They attributed this to the fact that through online multimedia videos, it is often easy to cost-effectively illustrate the use and the values of the product to a wider audience. This renders it easy for some of the SMEs to differentiate their products from rival products. Such a finding was mainly common in some of the narratives to the interview question that evaluated the values of experiential marketing. In the quests to leverage customers' brand attachment, some of the marketing managers explained that the motive of such communication is often just to adore and praise the product so that the general public can get aroused and more attached to the brand. As some of the SMEs use such an approach, it was, however, not evident from the findings that any initiatives are undertaken to discern how customers feel about the product. Instead, businesses that use such approach seem to only focus on influencing the improvement of customer attachment to the brand rather than for discerning the changes that can be undertaken. Such findings certainly imply that as businesses strive to bolster their sales and revenues, the motive of experiential marketing is usually just to accomplish that and not to diagnose and identify any new information that can be used for brand revitalisation and repositioning. From the thematic analysis of the findings, such a view was also shared by some the marketing managers who noted that their experiential marketing initiatives are often only aimed at leveraging marketing capabilities.

\section{Leverage marketing capabilities}

Instead of using experiential marketing to bolster brand revitalisation and repositioning, it emerged from the findings that some of the SMEs just tend to use experiential marketing to leverage their marketing capabilities. Explanations from some of the marketing managers indicated that experiential marketing is often used to supplement the roles played by the traditional marketing mechanisms such as television (TV), newspaper and FM radio advertisements. In such analysis, one of the marketing managers from the clothing retail sector argued that their marketing approach is designed in the way where television advertisements are aimed at reaching 'home lovers' that like to spend their evenings or weekends watching television. Whereas newspaper advertisements are aimed at reaching the elites and affluent working class, she argued that FM advertisements are meant for the motorists because it is increasingly emerging as a habit of the population to rather listen to FM radio when driving than when at home or work. As such advertisement and marketing strategies are being used, she noted that a huge market that constitutes of the young 'tech-savvy' and the growing online market is often ignored. To respond to such a gap, she explained that most businesses often apply a strategy of developing multimedia videos through which different products are demonstrated and marketed through the retail outlet's website or using social media platforms. Such a finding was also common in most of the responses to the interview question that explored the reasons why SMEs prefer to use certain experiential marketing methodologies.

In such responses, some of the marketing managers pointed out that the use of experiential marketing methodologies such as online product demonstrations enabled the business reach several consumers that cannot easily be reached through the traditional television and newspaper marketing mediums. In such explanations, most of the marketing managers pointed to online groups such as the youths that can best be reached through online marketing because of their constant online presence. Online marketing using different web applications was also reiterated to enable people to relate to the product better during their private hours, as compared to personal selling and demonstration that tend to bother and inconvenience customers at wrong hours. Such findings imply the use of experiential marketing methodologies such as online marketing as well as multimedia videos to demonstrate the product's usage and to create an awareness that supplements the roles of the traditional television, newspaper and radio marketing to leverage a firm's overall marketing capabilities. This view was accentuated in the opinions of a marketing manager 
with the work experience of eight years in the electronics assembling and manufacturing plant who stated:

'In addition to newspaper advertisements, we also use a combination of online marketing and social media marketing videos to create awareness about the availability of our products. That means if we cannot get you in the newspaper, we shall get you on the web. With web advertisement, the advantage is that most of the people are now on the web. Hence, it is the best place to advertise and search for customers.' (Male, 33, marketing manager)

Although the use of online experiential marketing methodologies was found to be common in the findings, there was also glaring evidence that some of the SMEs did not recognise that they were using experiential marketing. As most of the SMEs explore and discern the best ways for advertising and marketing their products, they were found to accidently engaged in the use of different experiential marketing methodologies without recognising that they are actually using one. This lack of understanding of the concept of experiential marketing affects most SMEs' capabilities to optimise experiential marketing to not only promote sales and profit maximisation but also gain insights into customer perceptions of their products. This limits the discerning of the product or strategy modifications that can be further undertaken to bolster the effective market performance of the struggling products. Such a finding was accentuated in one of the responses to the interview question that examined the challenges that SMEs' usually experience when using experiential marketing. In such responses, one of the marketing managers noted that there is a challenge of understanding the concept of experiential marketing in even a single marketing department. He explained that whereas some of the senior sales personnel and marketers interpret experiential marketing to only require the use of social media demonstration videos, to some, experiential marketing can also be used in the traditional television advertisements. He stated that this can be accomplished by making the advertisements real to arouse the connections and emotional attachments between the product and the customer. Even though such an interpretation of the concept of experiential marketing may be correct, there, was, however, also little evidence that most of the SMEs seize such opportunities to explore what customers are thinking about their products. After using more attractive and emotionally connecting advertisements, most of the SMEs were found to be more concerned about the sales. If the sales are positive, some of the SMEs were found not to be much concerned about what the customers are thinking or saying. Such a view was echoed in one of the responses to the interview question that explored how SMEs use the customer opinions and perceptions gained during experiential marketing to influence any review and change in the product, and the business approach that the business subsequently adopts. In that response, one of the marketing managers with work experience of 12 years in the retail sector noted that:

'Quite often, it is not what the customer is saying or thinking that matters. It is the sales. Good advertisements are measured by the immediate sales that they produce. If the sales are good, we do not focus much on getting inputs from customers because we know that almost most of the customers are satisfied. A business cannot satisfy everybody, somehow, someone will complain even when everything seems fine. But if sales are bad, we try to listen to customers to see the areas that can be changed and improved.' (Female, 36, marketing manager)

Even if that is not the challenge, some of the marketers still emphasised the difficulty of the challenge to overcome the lack of a system for tracking and collecting data on customer opinions. Investment in such a system was found to be costly for SMEs. Yet, as some of the SMEs accidentally use experiential marketing methodologies like multimedia videos to create awareness about different products, such advertisements were found not to be accompanied by a system for gathering and tracking customer opinions. On the contrary, one of the marketing managers revealed that even if such data are collected in conjunction with the customer views that are gathered from shows and demonstrations, constraints often still arise from how such data are utilised. In such instances, the collected data are often destroyed, either because the business is mainly focusing on sales or because they do not have the capacity to make the necessary changes, as they are not the manufacturers of the products that the customers are concerned about. These findings certainly signify that as some of the SMEs use different experiential marketing methodologies to leverage their marketing capabilities and boost sales, there seems to be less focus on understanding the experiential marketing methodology being used or how such methodologies can be used to gain insight into customer touchpoints that can be used to make the necessary brand diagnosis and changes to catalyse improvement of a firm's overall effective market performance. Yet, besides leverage of marketing capabilities and boost of sales, findings also revealed most SMEs to use different experiential marketing methodologies not because it aids understanding of the critical customer touchpoints, but because of the enormous cost advantages that it induces.

\section{Lower costs of marketing}

It emerged from the findings that some of the SMEs use experiential marketing as a strategy for reducing the overall marketing costs. In such initiatives, experiential marketing is often not used to aid the understanding of customer feelings and attachment to different brands, but just as a mere mechanism for lowering the often hefty costs of marketing. Even if some of the SMEs indicated to often utilise experiential marketing to gain insights into customers' feelings about the product, some of the marketing managers still argued that the fundamental motive for the application of experiential marketing methodologies such as online multimedia videos that promote the product or promotion shows, is usually to lower the overall costs of marketing. As compared to the costs of the traditional television, FM radio and newspaper advertisements and marketing, experiential marketing using mainly online multimedia videos that promote the product or promotion shows was found to lower the overall costs of marketing. This enlarges the overall profitability margins. 
Such a finding was corroborated in the opinions of a marketing manager with the work experience of 10 years in the sanitary manufacturing plant who stated that:

'The use of online multimedia videos or promotion shows to promote the product is less costly as compared to television or newspaper advertisements that ask for a lot.' (Male, 44, marketing manager)

In such an instance, experiential marketing tends to be more cost-effective for some of the SMEs that are often constrained by the challenge of lack of critical financial resources. Such views were mainly common in the responses to the interview question that explored why SMEs prefer to use different experiential marketing methodologies. In such responses, the traditional television, FM radio and newspaper advertisements and marketing were reiterated by some of the marketing managers to be quite costly for a limited round of advertisements. In effect, when undertaken over a long period of time, it tends to affect cost savings as well as the profitability levels. To reduce costs, one of the marketing managers stated that the emergence of the internet offered some of the experiential marketing methodologies where information and details about the products and other value offerings of the business are recorded in multimedia videos. These videos are subsequently loaded onto the company's website, social media or YouTube where the videos are spread to billions of consumers almost instantly at relatively very low costs. Yet, as such online multimedia videos keep on playing and getting shared by customers all the time, the business incurs no additional costs for billions of customers to watch and re-watch the videos several times. As customers keep on sharing such advertisement videos, one of the marketing managers argued that it also tends to 'cause more persuasive effects on customers' decisions to visit the stores to make purchase'.

In effect, for some of the SMEs that do not have sufficient funds, online multimedia advertisements were found to be more preferable not as the strategy for understanding customer perceptions and feelings about the product, but as a medium for promoting the product. In contrast, for SMEs that are prepared to commit sufficient funds to an advertisement, experiential marketing entailing the use of multimedia videos and promotion shows was mainly found to be preferable as a back-up strategy. In such an approach, a marketing manager with the work experience of 9 years in the housing utensils' manufacturing plant elaborated that:

\footnotetext{
'...the business uses some bit of television, newspaper or FM advertisements, and thereafter takes the opportunity to refer the public to its online videos that are on its website, social media or any online platform for more details.' (Female, 37, marketing manager)
}

This form of integrated advertisement and marketing approach was noted by some of the marketing managers to significantly persuade customers to make a purchase. At the same time, findings indicated the use of experiential marketing methodologies such as promotional shows to enable customers experience the product without bothering the customer in any way.

However, as much as the motive for all these initiatives is to boost sales, profitability, lower costs and leverage a firm's overall marketing capabilities, only a few SMEs indicated that they also use experiential marketing as a means of understanding customers' feelings to determine the necessary product or strategy modifications that can be undertaken.

\section{Value of small and medium-sized enterprises experiential marketing}

As most of the SMEs tend to use experiential marketing to aid sales and profitability maximisation, findings still indicated risks of brand maturity and declining sales that threaten a business' sustainability to spur some of the SMEs to use experiential marketing to diagnose critical satisfiers or dissatisfiers, as well as the overall effectiveness of a firm's internal capabilities and strategies to determine product or strategy modifications that can be undertaken to reposition and revitalise the performance of the struggling brands. Such a view emerged from the second discourse that was extracted from themes that indicated meanings that were analogous to the values of SMEs' experiential marketing. Based on the results of the analysis where the discourse of experiential marketing's values was divided in two subdiscourses that encompassed satisfiers' and/or dissatisfiers', as well as the firm's strategies diagnosis, the details of the findings are as follows.

\section{Diagnosis of satisfiers or dissatisfiers}

Findings revealed experiential marketing to aid diagnosis of the satisfiers that attract customers to the product or dissatisfiers that repel customers from the product. While using experiential marketing methodologies such as shows and demonstrations, one-on-one marketing or interactive online multimedia systems, experiential marketing was found to enhance the initiation of interactive conversations with customers. Through these interactive conversations, findings indicated that marketers are often able to easily discern symptoms of satisfaction or dissatisfaction with the product. Yet, as customers are allowed to touch and feel the product when using experiential marketing methodologies such as shows and demonstrations or one-on-one marketing, some of the marketing managers noted that it also often becomes easier to not only gauge customers' emotional attachments to the product but also identify dissatisfiers. This creates the basis for exploring and probing further the reasons why some customers feel satisfied or dissatisfied with the product. It is through such a diagnosis of the satisfiers or dissatisfiers that some of the SMEs are often able to discern how the existing products can be improved or augmented to attract dissatisfied customers. Such views were mainly common in most of the participants' narratives to the interview question that explored whether SMEs use experiential marketing to gain insights into customer 
opinions and perceptions about certain aspects of their products and business approaches. However, one of the marketing managers noted that even if customers are impressed with the product, the reasons why they are contented with the product is still often critical for identifying the critical customer touchpoints that the business must focus on to catalyse the positive effects of experiential marketing on sales increment. Such a finding was common in most of the responses to the interview question that examined how the customer opinions and perceptions gained during experiential marketing influence any review and change of the product and the business approach that the business subsequently adopts. Even though some of the SMEs indicated that they often tend not to utilise such results to make any necessary change and modifications of their brands or marketing strategies, a marketing manager with 13 years' work experience in the chocolate and dairy products' manufacturing plant explained that:

'Experiential marketing offers sort of a survey for the business to understand the needs and demands of its customers. Using direct demonstration of the products, a business is able to initiate conversation with the customers as they interact with different products. Even when customers are not honest in their opinions, it is often easy to assess from their body language how they feel about the product. One can also over hear them converse about the product. As for the online multimedia videos that demonstrate different products, it is usually easy to gain insight on how the general public feels about the product. This is because they are able to watch the videos from any place of their comfort and in effect they are usually free to comment. This renders it easy for the business to gauge the general response of the public to the product. If it is positive, then, the business thrives, if it negative, it may require change of a few things to change things around.' (Male, 44, marketing manager)

As marketers use such interactive platforms as survey mechanisms to understand customer opinions and touchpoints, it also offers opportunities for marketers to discern aspects of the product features, designs, attributes and quality that the customers are not that very much impressed with. It is through such an analysis that the SMEs are often able to reconceptualise and review how the overall attractiveness of the existing product features, design and quality can be modified to entice and instigate the required customer emotional attachments. This leverages brand repositioning by reviewing and modifying the product to respond to market needs and demands that were previously not anticipated. It also enhances the review and revitalisation of the performance of the poorly performing brands. From the analysis of the findings, such an approach was found to be quite evident among the SMEs that are involved in the development of products. In the development of products, some of the marketing managers reiterated experiential marketing to offer critical real-time customer feedback that enables businesses to undertake the often cyclical process of developing and market testing the product until the final acceptable version is reached. Such a view was echoed in one of the narratives in the responses to the interview question that explored the types of changes that are usually influenced by the customer opinions and perceptions that are gained during experiential marketing. In one of such narratives, a sales' representative who had worked for a baby formula manufacturing SME which is based in Midrand, Gauteng for seven years, stated that:

'In our experience as the developers and manufacturers of baby formulas, we have found that each time a new formula is developed; experiential marketing using shows and demonstrations often play critical roles towards highlighting major customer concerns that may be impressive or not impressive about our formulas. So, using such findings, we often go back to the drawing board to assess how the concerns raised by the customers can be integrated in the redesign and new quality considerations and features. Experiential marketing helps not only in the cases of new innovations, but also for discerning the causes of the declining market performance of our older brands. In case, some of the older brands are not performing well, we often conduct promotions and shows at malls in which we not only give certain products for free or at reduced prices, but also get our sales personnel to intensely engage with customers, so as to identify their feelings about our products. In this process, such interactions aid the analysis of whether customers' feelings have changed positively or negatively or it has since remained constant. If customers' feelings have changed negatively, sales personnel are often further instructed to probe why it is so. Is it because of a new rival brand, or new negative developments that the customers have discovered about the consumption of our product?' (Male, 36 , sales' representative)

Such a finding corroborates the views of the other SMEs that indicated that they use experiential marketing not only to assess customer feelings and emotional attachments to the products but also as a framework for diagnostic factors explaining a brand's poor market performance. Even if the brand was found to be performing well, some of the participants reiterated that their businesses often still use the results of experiential marketing to assess the extent to which the features and quality of the product can be improved to leverage its overall market competitiveness. It is such brand modifications that reposition the brand to attract more customers from the existing as well as new market segments. It also aids revitalisation of the performance of the brands that are almost sliding into declines. However, one of the marketing managers argued that as much as most initiatives for brand repositioning and revitalisation arise from the negative points that customers have raised across different interactive platforms, in some of the cases, such negative comments may tend to be unreliable. He explained that it is not advisable for businesses to rely on such comments without correlating them with sales to assess whether the sales are also affected. He attributed this to the fact that in some of the cases, positive comments may be received about a particular product which is being marketed using online multimedia videos, but such positive comments often never translate into sales increment. In contrast, he stated that there are also instances where despite negative comments about the product, sales have often not been affected. In such cases, if positive comments do not translate 
into higher sales, the marketing manager with work experience of nine years in the glass products' manufacturing plant stated that:

'It is critical to assess the actual causes of such situations. It could be arising from the fact that the videos have been over-augmented to reflect the product in a way which is different from its actual physical appearance. Hence, when customers see the video and rush to buy the product, they find something else. In effect, for us, whether it is positive or negative comments, we usually wait for sales to be affected before taking actions to address the areas of customer dissatisfactions or concerns.' (Male, 42, marketing manager)

Meanwhile, some of the other marketing managers noted that even though they often strive to integrate customer views from experiential marketing to undertake relevant product modifications, major constraints have often still arisen from the cost of implementing the required product modifications. Such views were common mainly in some of the responses to the interview question that explored how SMEs use the views from experiential marketing to make changes that influence the improvement of their performance. In such responses, experiential marketing was reiterated in certain cases to reveal customer perceptions and expectations that are totally at variance with the design, quality and features of most of the existing product offerings. In effect, capabilities to respond to such customer opinions and perceptions were noted by some of the marketing managers to require significant change that not only disrupts the normal flow of activities but also requires enormous financial resources. Such a view was corroborated, not only by some of the themes in the third discourse on experiential marketing challenges, but also by some of the narratives in the responses to the interview question that explored the challenges that SMEs usually experience when undertaking necessary changes to revitalise the performance of their products or businesses that are not doing well. Even if some of the SMEs have sufficient finances to implement the required product changes and modifications, it still emerged from such narratives that executives' inflexibility and lack of agility often emerge as major constraints. The implications are often latent in the fact that even if brand modifications are required, they are often only undertaken when it is quite late to reposition or revitalise the performance of the struggling brands. However, if SMEs are not using the results of experiential marketing to undertake necessary to diagnose satisfiers and dissatisfiers in order to review and modify the product, they were found to use such results to turn around not only the performance of the struggling brands but also the performance of the entire business.

\section{Diagnosis of a firm's strategies}

As experiential marketing offers insights that explain a product's poor performance, it was also found to instigate the diagnosis of the effectiveness of a firm's strategies. Such a view is accentuated by the fact that during discourse analysis and extraction, some of the narratives were found to indicate that as the motives of the application of experiential marketing methodologies are often to improve marketing capabilities to turn around poor performance as well as declining sales and profitability, quite often, it is similar themes that instigate the use of experiential marketing to make necessary diagnosis. If the cause of a brand's poor market performance arises from pricing that may not be relatively competitive, views from some marketing managers were found to instigate the review and modification of a firm's cost variables. As one of the marketing managers noted, such reviews and changes may encompass process changes, reduction of personnel as well as advertisement costs or undertaking any change that would unlock cost advantages. Such cost advantages can be passed on to customers in the form of lower prices to revitalise the performance of the struggling brand. Such views were mainly common in some of the responses to the interview question that explored the types of changes that are usually influenced by the customer opinions and perceptions that are gained during experiential marketing. However, as contrasted to the SMEs in the retail sector, such an approach was found to be commonly undertaken by the SMEs in the manufacturing sector. Small and medium-sized enterprises in the manufacturing sector are often more able to easily modify and change their cost variables as compared to those in the retail sector. Such views were corroborated in the opinions of a marketing manager with five years' work experience in the retail sector who explained that:

'If customers are complaining about the high prices of the products, there is nothing much that we in the retail sector can do. In most of the cases, our prices are calculated to include all the costs that we incur. Hence, the solution is usually to go back to the manufacturers and request for more discounts. If they don't accept, the only option is to clear and discontinue the product. As compared to us, manufacturers can easily change prices because they have so many things that they can do to reduce costs and lower prices.' (Female, 26, marketing manager)

In contrast, findings indicated that if the results of experiential marketing indicate declining level of brand maturity, then it influences decisions about the modifications of the existing marketing strategies or conceptualisation of new marketing strategies that can be applied. For declining brands, findings imply that some of the marketing strategies' review and modifications have often entailed that the review and modification of some of the marketing strategies have often entailed lowering prices to clear out declining brands. Alternatively, some of the marketers suggested that it may also involve approaching new markets in new geographical locations where such brands may still be perceived as relatively new. If all these are not able to revitalise the performance of the declining brands, then product change and modifications are often undertaken to add new features and attributes that render the product more responsive to the changes in market trends that have unfolded since the product's launch. They attributed this to the argument that from intense interactions with customers during experiential marketing, they are often able to identify whether customers are already tired of the existing product versions or they are still more interested in them. Such views were mainly 
common in the responses to the interview question that explored how the customer opinions and perceptions gained during experiential marketing influence any review and change of the product and the business approach that the business subsequently adopts. In such an analysis, it was reiterated that if the poor market performance of the brand is not arising from customers' dissatisfaction with the product's features and attributes, then the challenge could be emanating from the poor marketing strategies being used. Such poor marketing strategies may arise from poor distribution where, although products are required by certain customer segments in a particular region, the distribution system and networks being used often do not aid the distribution of products to such locations. This often aids the review and modification of particular segments to target, as well as that of the distribution, promotional and pricing strategies. This view was accentuated in the opinions of a sales representative with eight years of work experience in a shoe manufacturing SME in the Western Cape, who stated that:

'From the interactions with customers, some of the customers may appreciate or complain about the quality, features and designs of the products. Others may raise issues about the pricing of the product that may be unreasonably too high or the poor accessibility of the customers to the product, and incompetencies of the sales force causing poor service quality. While others may complain about lack of awareness of the product's existence as compared to rival brands. Using this information, it is usually for the marketing manager to assess the intervention measures that can be undertaken. From my experience, I feel that experiential marketing is of significant importance because it enables one to understand not only the product and the customer, but also the overall market.' (Male, 38, sales' representative)

However, it also emerged from the findings that experiential marketing aids not only the review and modification of the external marketing strategies to reposition and revitalise the product but also review and modification of a firm's internal marketing strategies. To accomplish this, the participants noted that in-store marketing is one of the techniques that they use. In this process, factors such as lighting, display, smell, cleanliness and attractiveness of the overall in-store environment are often used as part of the initiatives for gauging customers' experience and satisfaction, not only regarding a product's quality but also the environment in which such products are offered. If customers are found not to be impressed, this enhances the review and modification of the in-store facilities and environment as part of the strategies for repositioning the product as offering new value. In case, the brand was declining, it also offers opportunities to revitalise brands that are almost sliding into declines. In other words, such a finding suggests experiential marketing can offer the foundational information that can enable the executives to sense threats and undertake necessary pro-active measures to thwart such threats. However, the effective application of such pro-active intervention measures would require management flexibility and agility which most of the marketing managers emphasised that most of the SMEs to lack. This undermines the values that experiential marketing offers to highlight the future threats that SMEs need to thwart if they are to operate more sustainably. Such a view is corroborated in most of the responses to the interview question that evaluated the challenges that SMEs' experience when using experiential marketing. In such responses, the marketing manager with 13 years' work experience in the retail sector reiterated that:

'Management is used to hearing customers say this and that about the product and the business. As time goes on they become immune to the extent that even when the customers are raising valid points, they tend to ignore it until the product is being bought just by a very few groups of customers. It is at that point that they start to think about clearing such a product and introducing new ones. They want to be sure that the product or the business is no longer performing very well before discontinuing it or making the required changes.' (Male, 47, marketing manager)

Some of the participants revealed the rationale behind such approach to be latent in the executives' fear to make changes that cause uncertainties and interfere with sales and revenues. In effect, findings revealed most of the executives to be quite slow, inflexible and less agile when seeking to conceive and implement new strategies that can cause brand repositioning and revitalisation. Yet, as the executives remain largely inflexible and less agile, evidence of brand declines that are often identified during experiential marketing tends to worsen over time, thereby rendering it not reasonably possible for the executives to intervene and undertake strategies that could reposition and revitalise the struggling brands. Despite such challenges, there was nonetheless mundane evidence from the findings that indicated that SMEs' experiential marketing behaviours often enhance product review and modification, as well as marketing strategies' review and modifications to edify the repositioning and revitalisation of the struggling brands.

\section{Discussion}

Experiential marketing is critical for bolstering a firm's performance. It supplements the role of the traditional television, newspaper and radio advertisements and marketing. As businesses use experiential marketing methodologies such as online marketing and multimedia videos that demonstrate a product's overall value offerings, experiential marketing catalyses the market's awareness of the product, as well as the locations where such products can be obtained. This generates not only sales and profitability increment but also enrichment of customers' brand attachment. Such a view is at tandem with Gronlund's (2013:19) argument that experiential marketing aids the identification of customers' emotional triggers and attachment to the product that can be used to catalyse a product's overall effective market performance. The use of experiential marketing methodologies such as online marketing and multimedia videos also lowers the overall marketing costs. It enables less financially resourced businesses such as SMEs to avoid the often hefty costs of 
television and newspaper advertisements. All these may leverage returns on the shareholders' value. Experiential marketing also offers the interactive interface between the salesforce, customers and products. This enables businesses to diagnose the overall level of customer feelings and attachment to its different brands.

Unfortunately, in most of the enterprises, the use of experiential marketing methodologies such as shows and demonstrations, as well as online marketing and multimedia videos are often only limited to influencing the achievement of the basic business outcomes such as sales and profitability increment. Such experiential marketing methodologies are also often used in the quests to aid minimisation of the traditionally often hefty cost of marketing. Limiting experiential marketing to only the achievement of such basic business outcomes renders it difficult to discern and identify the igniters or the inhibitors of a brand's performance. Yet, survival in the increasingly precarious contemporary business environment requires SMEs to constantly evaluate and understand the overall effectiveness of the market performance of their different brands (Kolbl et al. 2015:7; Zarantonello \& Schmitt 2014:255). Such analysis edifies identification of the areas that entice or constrain customer experience and satisfaction with the brand. It is through the identification of such areas of dissatisfaction that SMEs are often able to undertake new strategies or modify the existing strategies to reposition and revitalise declining brands.

Even though in such analysis, most businesses often rely on brand evaluation, the use of experiential marketing is still critical for marketing executives to gain insight into the overall level of customer experience, emotional attachments and satisfaction with the brand. Conventionally, the motive of experiential marketing is to promote and sell a product to the target market segments. However, as it uses intense customer-product interactions to diagnose and improve customers' emotional attachment to the product, experiential marketing also aids real-time analysis of the overall state of a brand's effective market performance. From such analysis, it often turns evident whether the brand is performing poorly or about to slide into decline even. If the brand is performing poorly or about to slide into decline even, it enhances brand review and the eliciting of critical information that in turn aids brand reinvention, innovation, replenishment and improvement of the performance of the struggling brands (O'Sullivan, Richardson \& Collins 2011:891; Sugimori, Matsuda \& Kusumi 2011:42). It is the application of such strategies that leverages a brand's repositioning and revitalisation.

Information gained from experiential marketing also tends to be critical for repositioning and revitalising a brand through relevant modifications to match the emerging changes in customer tastes and preferences. It also leverages brand redesign, reinvention of brand identity and innovative advertising (Gronlund 2013:19). Experiential marketing methodologies such as one-on-one marketing and the use of interactive multimedia also elicit critical insights that businesses can use to refresh the visual aspect of the brands considered to be declining. Yet, as marketing personnel interact with different customer groups, their views often also influence how strategies such as the development of new distribution networks, marketing of the brand in new markets or market segments, and expansion of the brand's portfolio of products can be used to revitalise the performance of the struggling brands (Brown 1999; Cova \& White 2010:256; Toledo \& Evandro 2013:33). In other words, it is quite evident that experiential marketing not only aids brand diagnosis but also aids acquisition of critical information that influences how the struggling or the poorly performing brands can be repositioned or revitalised. Based on such analysis, it seems the study has responded to its fundamental research questions which were to explore whether SMEs' experiential marketing behaviours enhance brand diagnosis, repositioning and revitalisation, as well as the various types of changes undertaken and the challenges of bringing about such changes. However, considering that only little seems to have been undertaken to evaluate the leveraging effects of experiential marketing on brand repositioning and revitalisation, a challenge still arises from the inadequacy of the model that SMEs can replicate.

\section{Contribution of the research}

To deal with the challenge of an inadequate framework which SMEs can replicate when using experiential marketing to leverage brand diagnosis, repositioning and revitalisation, Figure 1 offers valuable practical insights on what the SMEs need to do to utilise their experiential marketing mechanisms to diagnose how their struggling brands can be repositioned and revitalised. It is argued in Figure 1 that as experiential marketing is being used to promote sales and profitability increment, the SMEs can also use experiential marketing to diagnose and identify customer satisfiers and dissatisfiers. Diagnosis and identification of satisfiers and dissatisfiers are pillars for discerning how each of the brands is performing. To accomplish this, it is critical to use the interactive salesforce-customer interface to assess whether the major customer satisfiers or dissatisfiers are arising from product quality, customer service quality, product availability, pricing, comparison with competitors' brands, product obsolescence and marketing communications. Such analysis must still be accompanied by the diagnosis of the effects of such dissatisfiers or satisfiers on a brand's competitiveness, sales, revenue and profitability. This is attributable to the fact that in certain cases, a majority of customers may express negative opinions about a particular product, but such negative perceptions often never translate into factors that undermine a brand's competitiveness, sales, revenue and profitability.

In effect, such analysis aids the evaluation and identification of the struggling brands as well as the well-performing brands. This paves the way for the identification of the brands that must be subjected to a thorough analysis during experiential marketing to assess the reasons that are causing 


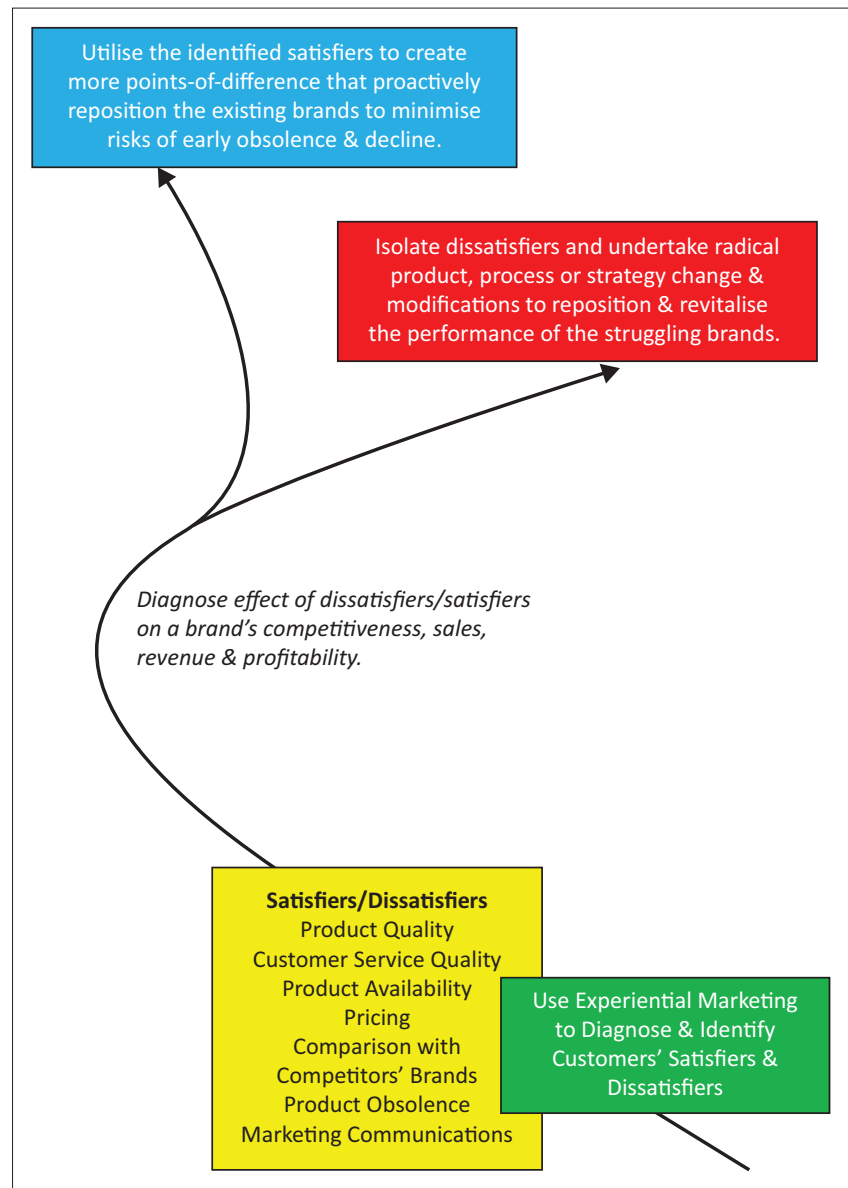

Source: As derived from the interpretation and triangulation of the interview findings in theories on experiential marketing and brand repositioning and revitalisation of Iglesias, 0 . Singh, J.J. \& Batista-Foguet, J., 2011, 'The role of brand experience and affective commitment in determining brand loyalty', Journal of Brand Management 18(8), 570-582. https://doi. org/10.1057/bm.2010.58; Masterman, G. \& Wood, E.H., 2008, Innovative marketing communication strategies for the events industry, Heinemann, Oxford and Murane, P., 2012 7 steps to revitalize your brand, BrandJuice, New Delhi, India.

FIGURE 1: Experiential marketing framework as a basis for brand repositioning and revitalisation to enhance small and medium-sized enterprises sustainability.

the declining performance of such brands. In such an analysis, some of the experiential marketing techniques may require the use of in-store marketing, the use of sales personnel, online interactive multimedia videos and query platforms, telemarketing, as well as shows and promotional marketing (Zarantonello \& Schmitt 2014:255). The application of these experiential marketing techniques may be accompanied by the creation of an environment and systems that facilitate customer-product interaction, customer immersion, as well as the use of experiential marketing events.

For brands that are identified to be performing poorly, it is critical to isolate major customer dissatisfiers and undertake radical product, process or strategy change and modification to reposition and revitalise the performance of the struggling brands. Brand repositioning and revitalisation strategies that the SMEs' marketing executives can undertake to ensure the brand matches the changes in customer tastes and preferences may require brand redesign and reinventing brand identity. It may also require innovative advertising, refreshing of the visual aspect of the brand and development of new distribution networks. As derived from Light and Kiddon's (2009) brand revitalisation model, the other strategies may also have to entail marketing of the brand in new markets or market segments, and expansion of the brand's portfolio of products. As SMEs' marketing executives also review and redesign product features, design and quality to delight and entice customer experience, it is however also critical that sufficient financial resources is dedicated in conjunction with the development and entrenchment of a culture of flexibility and agility to support constant brand review and modification. Even if some of the brands are identified to be performing well, it is still of significant importance that the customer satisfiers that influence such a brand's performance are identified and further modified to create more points-of-difference that proactively reposition the existing brands to minimise risks of early obsolescence and decline.

\section{Conclusion}

In this study, the fundamental research questions were to explore whether SMEs' experiential marketing behaviours enhance brand diagnosis, repositioning and revitalisation as well as the types of changes made and the challenges of such changes. From the analysis of the findings, it seems the study has succeeded to respond to such questions. It was easily discernible that experiential marketing leverages not only marketing effectiveness but also the diagnosis of customer opinions and perceptions about the various other aspects of the business. Through such an analysis, it also aids diagnostic brand reviews. Constant brand review and modification are pivotal to leveraging SMEs' performance in the increasingly changing modern markets. It aids a firm's capabilities to respond to the constantly changing customer tastes and preferences as well as the proliferation of increasingly disruptive innovations. Constant brand review and modification also minimise the often inherent risks of product obsolescence. In the quests to bolster a firm's continuity and sustainability, constant brand diagnosis is critical for understanding and identifying the critical aspects of the brand that must be changed and modified to turn around the market performance of the declining brands. Even though some of the SMEs often use surveys, experiential marketing is increasingly emerging, not only as a marketing strategy for promoting sales and profitability maximisation but also as a mechanism for diagnosing the causes of a brand's poor market performance. As experiential marketing is being used to leverage sales and profitability increment, it also enhances the analysis and identification of the major customer touchpoints and triggers that can be improved to stimulate customer emotional attachment to the product. It also influences the identification of the incremental improvement of the initiatives that can incrementally improve the level of customer loyalty, as well as sales, revenues and profitability. Experiential marketing unearths underlying constraints that are undermining a brand's effective market performance. It explores the level of positive emotional attachment to different brands that customers experience. However, as it 
aids such an analysis, experiential marketing also offers SMEs the opportunities to undertake brand diagnosis to identify a combination of strategies that can be utilised to reposition and revitalise the performance of the poorly performing brands. Such constant brand repositioning and revitalisation may, however, require the use of an appropriate experiential marketing model. Unfortunately, findings revealed that the issue of such a model is a challenge that still confounds most of the contemporary SMEs' marketing executives. In effect, by suggesting the experiential marketing framework in Figure 1, this research sought to address such a challenge. However, future studies can still explore the critical factors for edifying SMEs' brand repositioning and revitalisation in the increasingly precarious contemporary global markets.

\section{Acknowledgements Competing interests}

The author declares that he has no financial or personal relationships which may have inappropriately influenced him in writing this article.

\section{References}

Adeosun, L.P.K. \& Ganiyu, R.A., 2014, 'Experiential marketing: An insight into the mind of the consumer', Asian Journal of Business and Management Sciences 2(7), 21-26.

Alkilani, K., Ling, K.C. \& Abzakh, A.A., 2013, 'The impact of experiential marketing and customer satisfaction on customer commitment in the world of social networks', Asian Social Science 9(1), 262-270.

Anderson, J.C., Kumar, N. \& Narus, J.A., 2007, Value merchants: Demonstrating and documenting superior value in business markets, Harvard Business School, Boston, MA.

Aronne, C.V. \& Vasconcelos, M.C.R.L., 2009, The impact of experiential marketing on the customer's perception of a brand's essence, Encontro da ANPAD, Autoria, Brazil.

Babbie, E., 2008, The basics of social research, Thomson Wadsworth, Belmont, TN.

Babbie, E. \& Mouton, J., 2008, The practice of social research, Oxford University Press, Cape Town.

Brown, S., 1999, 'Retro-marketing: Yesterday's tomorrows, today', Marketing Intelligence and Planning 17(7), 363-376. https://doi.org/10.1108/02634509910301098

Bryman, A. \& Bell, C., 2007, Business research, MacMillan, London.

Canniford, R., 2011, 'How to manage consumer tribes', Journal of Strategic Marketing 19(7), 591-606. https://doi.org/10.1080/0965254X.2011.599496

Carù, A. \& Cova, B., 2008, 'Small versus big stories in framing consumption experiences', Qualitative Market Research: An International Journal 11(2), 166-176. https:// doi.org/10.1108/13522750810864422

Chao, R.F. \& Kuo, T.Y., 2013, 'The influence of experiential marketing and brand image on consumers' revisit intention: A case study of E-DA Theme Park', Journal of Tourism and Leisure Management 1(1), 33-55.

Chen, Y.Y., Shek, D.T. \& Bu, F.F., 2011, 'Applications of interpretive and constructionist research methods in adolescent research: Philosophy, principles and examples', International Journal of Adolescent Medicine and Health 23(2), 129-139. https:// doi.org/10.1515/ijamh.2011.022

Cohen, L., Manion, L. \& Morrison, K., 2011, Research methods in education, Routledge, London.

Cova, B. \& White, T., 2010, 'Counter-brand and alter-brand communities: The impact of Web 2.0 on tribal marketing approaches', Journal of Marketing Management 26(3), 256-270. https://doi.org/10.1080/02672570903566276

Crain, D.W. \& Abraham, S., 2008, 'Using value-chain analysis to discover customers' strategic needs', Strategy \& Leadership 36(4), 29-39. https://doi.org/10.1108/ strategic needs', Strate
10878570810888759

Day, G.S., 2011, 'Closing the marketing capabilities gap', Journal of Marketing 75(2), 183-195. https://doi.org/10.1509/jmkg.75.4.183

Dev, L.S. \& Chekitan, S., 2012, Hospitality branding, Cornell University Press, Ithaca, NJ. https://doi.org/10.7591/cornell/9780801452031.001.0001

Fang-Chao, R., 2015, 'The impact of experimental marketing on customer loyalty for fitness clubs: Using brand image and satisfaction as the mediating variables', The Journal of International Management Studies 10(2), 52-60.

Fetterman, D.M., 2009, Ethnography: Step by step, Sage, Newbury Park, CA.
Gang, W., 2011, Brand management in SMEs, Department of Social Sciences, Midwest University, Midwest, Sweden.

Gronlund, J., 2013, Basics of branding: A practical guide for managers, Business Expert Press, New Delhi, India.

Gupta, S. \& Ramachandran, J., 2010, The Park Hotels: Designing communications, Indian Institute of Management, Bangalore.

Herrmann, J.L., Walliser, B. \& Kacha, M., 2011, 'Consumer consideration of sponsor brands they do not remember: Taking a wider look at the memorisation effects of sponsorship', International Journal of Advertising 30(2), 259-281. https://doi. org/10.2501/IJA-30-2-259-281

Hu, T.L., Ho, Y.H. \& Hsieh, W.C., 2014, 'A study on the relationship among trust, brand image, experiential marketing, and customer loyalty for department stores', Journal of the National Taipei College of Business 25(6), 55-75.

Iglesias, O., Singh, J.J. \& Batista-Foguet, J., 2011, 'The role of brand experience and affective commitment in determining brand loyalty', Journal of Brand Management 18(8), 570-582. https://doi.org/10.1057/bm.2010.58

Jain, S. \& Lohia, S., 2014, 'Experiential marketing: Emerging issues and suggestions', International Journal of Advances in Management and Economics 3(2), 197-203.

Jonk, G., Handschuh, M. \& Niewiem, S., 2008, 'The battle of the value chains: New specialised versus old hybrids', Strategy \& Leadership 36(2), 24-29.

Kanth, K.P.S.R., Maheswar, D.U.R. \& Venkatesulu, K., 2016, 'Brand revitalisation', International Journal of Science Technology and Management 5(1), 321-326.

Keller, K., 2013, Managing brands over time. Strategic brand management, Pearson, Upper Saddle River, NJ.

Keller, K.L., 2013a, Strategic brand management: Building, measuring, and managing brand equity, Prentice-Hall, Upper Saddle River, NJ.

Kolbl, Z., Konecnik, R.M. \& Kolar, T., 2015, 'Brand revitalization: Don't let your brands turn into sleepyheads', Central European Business Review 4(2), 5-11. https://doi.org/10.18267/j.cebr.121

Kotler, P. \& Armstrong, G., 2010, Principles of marketing, Pearson, Upper Saddle River, NJ.

Lee, T.H. \& Chang, Y.S., 2012, 'The influence of experiential marketing and activity involvement on the loyalty intentions of wine tourists in Taiwan', Leisure Studies 31(1), 103-121. https://doi.org/10.1080/02614367.2011.568067

Lefi, L. \& Gharbi, A., 2011, 'Nostalgia and brand attachment: Theoretical framework and application in the case of a Tunisian advertising', Journal of Business Studies Quarterly 3(1), 187-200.

Lekhanya, L.M., 2015, 'An exploration of the impact of digital marketing on SMEs growth and brand popularity in rural South Africa', Journal of Economics and Behavioural Studies 7(5), 37-42.

Light, L. \& Kiddon, J., 2009, 'Six rules for brand revitalization: Learn how companies like McDonald's can re-energize their brands', Pearson Education, Upper Saddle River, NJ.

Lincoln, Y.S. \& Guba, E.G., 2005, Paradigmatic controversies, contradictions, and emerging confluences, Sage, Thousand Oaks, CA.

Lockwood, T., 2010, Design thinking: Integrating innovation, customer experience and brand value, Allworth Press, New York.

Matthews, J. \& Bucolo, S., 2014, Continuous innovation in SMEs: How design innovation shapes business performance through doing more with less, Queensland University of Technology, Brisbane, Queensland.

Marzocchi, G., Morandin, G. \& Bergami, M., 2013, 'Brand communities: Loyal to the community or the brand?', European Journal of Marketing 47(1), 93-114. https:// doi.org/10.1108/03090561311285475

Masterman, G. \& Wood, E.H., 2008, Innovative marketing communication strategies for the events industry, Heinemann, Oxford.

Merchant, A. \& Ford, J., 2008, 'Nostalgia and giving to charity: A conceptual framework for discussion and research', International Journal of Nonprofit and Voluntary Sector Marketing 13(1), 13-30. https://doi.org/10.1002/nvsm.300

Murane, P., 2012, 7 steps to revitalize your brand, BrandJuice, New Delhi, India.

O'Guinn, T., Allen, C.H.T., Semenik, R.J. \& Scheinbaum, A.C., 2015, Advertising and integrated brand promotion, Cengage Learning, New York, NY.

O'Sullivan, S.R., Richardson, B. \& Collins, A., 2011, 'How brand communities emerge: The Beamish conversion experience', Journal of Marketing Management 27(9), 891-912. https://doi.org/10.1080/0267257X.2011.565684

Rootman, C. \& Zeka, B., 2013, 'The brand image and performance of small and medium enterprises: How can social responsibility activities help?', Acta Commercii 13(1), enterprises: How can social responsibility acti

Qader, I.K.A., 2013, 'The evolution of experiential marketing: Effects of brand experience among the millennial generation', International Journal of Academic Research in Business and Social Sciences 3(7), 331-340.

Russo, S.T., Carida, A., Colurcio, M. \& Melia, M., 2012, 'Store experience and co-creation: The case of temporary shop', International Journal of Retail and Distribution Management 40(1), 21-40. https://doi.org/10.1108/09590551211193586

Schmitt, B., 1999, 'Strategic experiential modules (SEMs)', Journal of Marketing Management 15(2), 53-67. https://doi.org/10.1362/026725799784870496

Sugimori, E., Matsuda, K. \& Kusumi, T., 2011, 'The contradictory effects of nostalgic advertisements on nostalgia for products and on remembering advertisements', Japanese Psychological Research 53(1), 42-52. https://doi.org/10.1111/j.14685884.2010.00454.x

Toledo, A.C. \& Evandro, L.L., 2013, 'Effect of nostalgia on customer loyalty to brand post-merger/acquisition', Bar 13(1), 33-55. 
Ward, A., Runcie, E. \& Morris, L., 2009, 'Embedding innovation: Design thinking for small enterprises', Journal of Business Strategy 30(2/3), 78-84. https://doi. org/10.1108/02756660910942490

Wynn, D. \& Williams, C.K., 2012, 'Principles for conducting critical realist case study research in information systems', MIS Quarterly 36(3), 787-810.

Xu, H., Larry, L., Harry, A. \& Dishman, P., 2015, 'Managers' perceived risk, experiential knowledge, marketing capability and international performance: A study of Chinese international enterprises', Journal of Marketing Development and Competitiveness 10(1), 53-65.
Yu, H.S., Zhang, J.J., Kim, D.H., Chen, K.K., Henderson, C., Min, S.D. et al., 2014, 'Service quality, perceived value, customer satisfaction, and behavioral intention among fitness center members aged 60 years and over', Social Behavior and Personality an International Journal, 42(5), 757-767.

Zarantonello, L. \& Schmitt, B.H., 2014, 'The impact of event marketing on brand equity: The mediating roles of brand experience and brand attitude', Internationa Journal of Advertising 32(2), 255-280. https://doi.org/10.2501/IJA-32-2-255-280

Zdravkovic, S. \& Till, B.D., 2012, 'Enhancing brand image via sponsorship: Strength of association effects', International Journal of Advertising 31(1), 113-132. https:// doi.org/10.2501/IJA-31-1-113-132 